\title{
Touch, Transcendence and Immanence in Film
}

\author{
By Andrew Murphie \\ Spring 2009 Issue of KINEMA
}

\section{TAKING OFF THE GLOVES: TOUCH, TRANSCENDENCE AND IMMANENCE IN FILM}

Beginning with excessive acts of both violence and compassion, as depicted in Martin Scorsese's Bring out the Dead (1999, USA), I attempt to sketch the play between transcendence and immanence in film. In particular, I am interested in Paul Schrader's philosophical discussion of "transcendental style", as well as his film work, and in the work of Scorsese, Yasujiro Ozu, and Gilles Deleuze concerning the film relations between transcendence and immanence. In the process I hope to foreground the role of touch in film and begin to question an aesthetic syntax in film and in philosophy. In a way the moment of bashing and compassion in Bringing Out the Dead that I shall begin with crystallises a history of ambiguity and anxiety surrounding issues of touch, immanence and transcendence. I shall try and tease out only a few moments in this history.

\section{High on a Cocktail of Vitamins}

A baseball bat to the body or unthinking compassion? Such incompossible worlds live side by side in the Martin Scorsese directed/Paul Schrader written film, Bringing Out the Dead. Parallelling Taxi Driver (1976, USA), this film should perhaps have been called "Ambulance Driver". It argues with Taxi Driver's transcendental nihilism, and at the same time picks up where it left off. In one of many scenes that are difficult to watch, a sociopath of a paramedic, Tom (Tom Sizemore), goes into dark corridor populated by homeless people and takes a baseball bat to Noel (Marc Anthony), one of the more unfortunate street characters in the film. Yet following this, the other paramedic, Frank (Nicolas Cage), pushes Tom away and, significantly in this age ungloved and unprotected, treats Nestor and gives him mouth-to-mouth (on a previous occasion Tom has worn surgical gloves while beating Noel up). Frank is high on a cocktail of vitamins (!), alcohol and injected adrenalin. He is beyond being burnt out by his work. He is haunted by a teenage girl, Rose, he could not save. Falling without thinking into compassion towards Noel, he is somehow embodying an excess that inhabits the situation. The film, likewise, seems to me to fall at this moment into an excess of immanence, an immanence that also exceeds the situation, somehow opening up the film, so that this becomes one of those filmic moments that is recovered to narrative only afterwards.

It is not that this scene is not given a explanatory context, despite the fact the scene exceeds the context given. In fact, we have been prepared for this scene throughout the film. It is the early 1990s, perhaps the most paranoid moment of the HIV/AIDS crisis, and earlier in the film, at their base, the paramedics discuss whether they have ever given mouth-to-mouth. If they have, it has been once, for example in one case this was to a baby. One paramedic cautions against it in drug overdose situations, saying that you can end up with a mouthful of "junkie puke". We also know a bit about Noel. We are told he is mad, that a drug dealer once put a bullet in his brain and that this seems to have taken him into madness, one sign of which is an insatiable thirst. We know that he says he wants to die. In an earlier scene he has cut himself with a broken bottle and, holding it to his own throat, his long hair soaked in blood, shaken blood all over Frank as he persuades him to come to the hospital. We have seen Tom (with gloves on) beat Noel up once before. We have seen Noel bash car windscreens with a baseball bat and later, Tom tries to "kill" his ambulance by bashing it. It is probably a measure of over twenty years' change in film that there might be a lot more violence in Bringing Out the Dead than there was in Taxi Driver. Yet Frank is not a psychopath like Travis in Taxi Driver, and Bringing Out the Dead is in some ways even more uncompromising in that the violence provides no narrative resolution as it does in the earlier film. The two together provide a wonderful example of repetition and difference. Maybe the making of Kundun (1997, USA) and his work on Tibet got to Scorsese. Or maybe there is something else at work here.

Many critics have pointed to the immanent nature of Martin Scorsese's films. In her wonderful book, The Scorsese Connection, Lesley Stern in particular has detailed the way in which the films make us "feel bodily and are moved outside our bodies" (9). Stern takes as her departure point "the question, of immediacy - the immediacy of touch" (14). She augments the Deleuzean formula from Cinema 2: The Time-Image for the 
"genesis of 'the bodily"" (12), pointing out that cinema will "dismember bodies" as a part of this "genesis", and even that "the film itself can materialise as a body of sorts, a body that bleeds". Stern also outlines the cultural position of touch according to Freud, a position in which the "totemic object...must not be touched for fear of its capacity for contagion and transference" (13). As with the scene described above, Scorsese's films seem particularly contagious, and they are drenched throughout with totems and fetishes. One could even say that in his films certain bodies themselves become immanent fetishes of the transcendent, whether that transcendent is one of heaven or hell, or just of the heaven or hell of the city of New York, as in so many of Scorsese's films, from Taxi Driver and Bringing Out the Dead, to The Age of Innocence (1993, USA) and Gangs of New York (2002, USA).

Laura U. Marks, in The Skin of the Film (2000), a study of intercultural cinema and touch, has noted the importance of the fetish object, which for her stands always between cultures, to intercultural cinema, and to a more "embodied" cinema. Scorsese is obviously not an intercultural film maker in the sense of Marks' book. Yet the New York of his films is heavily endo-colonised, and the rejuvenation of fetishism that Marks calls for in order to enable intercultural negotiation for the inhabitants of the cultural in-between seems strangely relevant here. Of course, New York in these films is not just full of intercultural fetishes and taboos, but in Scorsese's films the fetishes multiply and the taboos are nearly always being broken. There is not only palpable touch and embodiment in the films, but "contagion and transference" and a "dismemberment" of the body. We could almost say that the New York films deconstruct the their own central positions with regard to the intercultural - if deconstruction were not such a textual term perhaps so at odds with the fetish, and if we ignored the common position of white Americans at the centre of the films. Kundun (1997), a film of fetishes if ever there was one, could be interestingly compared with the New York films here. It does, however, run the risk perhaps of fetishising Tibetan culture as exotic rather than contagious and perhaps could be seen in the light of the reverse fetishisation of football in Khyentse Norbu's Tibetan film Phörpa (The Cup - 1999, Bhutan-Australia).

Any world of fetishes is one in which there is a constant collision of immanence and transcendence (the very point of the intensity of the fetish). Indeed, as if in combat with the excess of immanence, Bringing Out the Dead is full of ghosts, telepathy and the "Good Lord". Frank, for example, sees himself as God when he saves lives, but is haunted by visions of hell for most of the time. Yet if one was to think that the film supports an easy transcendence, nothing could be further from the truth. All of these figures are clearly made out to be just that - figures of speech, of imagination, filmic figures in fact, figures of the kinds of ambiguities that always stake out the territorialisations of transcendence within immanence. Scorsese's film shows us that neither transcendence nor immanence are easy, that we cannot easily inhabit either one of the other. For example, as if to undermine certainty in both directions, one of the paramedics, Marcus (Ving Rhames), a genuine true believer, somewhat manipulatively "resurrects" a drug overdosed teenager with prayer while directing Frank to administers the anti-narcotic, Narcan. Transcendence and immanence come together (at least in the form of Marcus' transcendent-immanent plan which is real in the sense that he impresses the teenager's friends), but they also annihilate each other in the process.

This confusion of transcendence and immanence is of course, a surprisingly common method in film, and we could again say that the history of this deliberate confusion of the two in cinema during the previous century usefully frames certain productive problems in contemporary philosophy and everyday life, the latter of which is arguably dominated by the cinematic (Stiegler). The confusion is one employed extensively and notably, for example, by Lars Von Trier, if only at times to frustrate his audience. Von Trier's television series Riget (The Kingdom -1994, Denmark), and Riget II (1997, Denmark), are perhaps clearest in this respect, dealing as they do with the rise of spirits into the midst of medical science - so that in one episode a "ghostly ambulance" regularly appears in front of emergency and quickly disappears, while in a much later episode this is explained as a strange trial in which hospital workers drive the ambulance with the windows whited out. Von Trier's work is of course heavily influenced by Carl Dreyer, and Von Trier reverses the play of transcendence and immanence, not just within his own work, but between it and Dreyer's. For example, the miraculous word of Carl Dreyer's Ordet (The Word - 1955, Denmark) becomes the miraculous flesh (in a film infected by misogynism) of Von Trier's Breaking the Waves (1996, Denmark) ${ }^{(1)}$. How can we explain such reversals of immanence and transcendence, found in so many films? It is at this point that I wish to recall Paul Schrader's theory of transcendental style. Not only is Schrader the writer of key films that 
Scorsese makes dealing with these issues, he has written Transcendental Style in Film (1972), a book that demonstrates a high regard for the work of Dreyer (as well as Ozu and Robert Bresson). I shall now turn to this book, as well as Schrader's own film making.

\section{Transcendental Bleeds}

It is surprising (or is it?) how often "transcendence" in the cinema relies on bodies, and indeed, on blood. This is the case in Schrader's 1997 film Touch (1997, USA). It is not a great film but it is an interesting film. It concerns a young Catholic monk called Juvenal (Skeet Ulrich) who finds, while a missionary, that he can heal with touch (in healings that are accompanied by the appearance of stigmata). This is something the film never really questions or even seems very interested in explaining. In fact, one seldom sees his magic touch in the film (though one does on occasion - the film does not hide it either). This is not because the healing touch is reserved for great moments but because it is not at the centre of the film. It is a mystery, but it is a banal mystery, and the film seems more concerned with how this works out in everyday life once the monk returns to the big city. I shall re-examine Schrader's thinking in this area because it is cinematically and philosophically complex, at times productively contradictory, and, I think, one of the most useful framings of the difficulties of discussing immanence and transcendence in the cinema. I am not suggesting that his thought of the early 1970s should be taken to task so much as qualified by what has come after, as much in his own cinematic work as in the theoretical work of others.

Schrader's Transcendental Style in Film (1972) discusses the work of Carl T. Dreyer, Robert Bresson and Yasujiro Ozu in order - not to describe the nature of the transcendent - but to outline the style by which it is given expression in film. Bresson and Dreyer's films in particular are full of obvious "transcendent" expressions and moments - vampires (Vampyr - 1932, France-Germany), miracles performed through words (Ordet), tortures and burnings at the stake (The Passion of Joan of Arc - 1928, France), a young girl inexplicably committing suicide by rolling down a hill into a pond (Bresson's Mouchette - 1967, France).

Schrader has a formula for transcendental style that expresses the movement towards these moments. For Schrader this style is used in many films (this is the power of his analysis) and is remarkably consistent (as opposed to the transcendent itself which is of course, elusive and unpredictable) although "few have had the devotion, the rigour, and the outright fanaticism to employ it exclusively" (10). In general --

Transcendental style seeks to maximise the mystery of existence; it eschews all conventional interpretations of reality: realism, naturalism, psychologism, romanticism, expressionism, impressionism, and, finally, rationalism... The enemy of transcendence is immanence..., whether it is external (realism, rationalism) or internal (psychologism, expressionism). To the transcendental artist these conventional interpretations of reality are emotional and rational constructs devised by man to dilute or explain away the transcendental. (11 - italics my emphasis)

How do you get away from these constructs and defeat the enemy of immanence? By reducing them as much as possible to stasis you change your speed relative to them and pass through to the transcendent. Schrader writes that -

Transcendental style stylizes reality by eliminating (or nearly eliminating) those elements which are primarily expressive of human experience, thereby robbing the conventional interpretations of reality their relevance and power. Transcendental style, like the mass, transforms experience into a repeatable ritual which can be repeatably transcended.

To fill out this process briefly, I should repeat that while the "beyond" may be the ultimate aim of transcendence itself, it is stasis that is the formal aim of transcendental style. In short, transcendental style is a style that limits culture and interpretation. This limitation defeats culture and interpretation, or at least the logic or sense in which we recognize them. Thus the transcendental is realised, or at least its possibility via transcendental form and style.

Of course, the possible universality of this style is immensely problematic, even if we cannot say that the transcendent itself is universal. Can we be certain that Bresson's transcendental style is the same as Ozu's, that a Jansenist version is the same as a Zen version, or even that the construction of transcendence/immanence barriers holds across cultures in the same way or even holds at all ? That there is some doubt as to whether 
it does is shown in several passages that precede and follow the kernel of Schrader's specific discussion of transcendental style.

He precedes this discussion with the well-known Zen aphorism "When I began to study Zen, mountains were mountains; when I thought I understood Zen, mountains were not mountains; but when I came to full knowledge of Zen, mountains were again mountains" (38).

Firstly, this return to mountains seems far from making immanence the enemy of transcendence (perhaps I am being naive). Secondly, this return to mountains is a long way from general notions of "Schraderian" transcendental style, and perhaps a particular formation of transcendence itself. These seem more realised in Bresson's films than most of his other examples ${ }^{(2)}$, where there is no return to nature, but an endless hostility between octants and their environment. The pond in which Bresson's Mouchette drowns herself seems so different here to the mountains in Ozu's films, or even the broader (and positively viewed) cultural world of boat travelling down a river as contemplated at the end of Ozu's Tokyo Story (1953, Japan). In short, although the style of East and West may come together in somewhat the same pattern for Schrader, the site and significance of the both the transcendental style and the "transcendent" seems very different, especially with regard to its relations to cultural and natural environments.

Schrader himself allows for such cultural difference in parts one and two in his formula (as I am about to describe it) but seems to have to gloss over it once we actually reach the apex of transcendental style (the stasis which opens out onto the transcendent) in the third part. Here cultural differences are rendered insignificant. He sets up a wonderfully productive binary-machine that excludes most of the rest of the world by including the East (Japan) and the West (France) within the Transcendent. He writes that "the East sought the Transcendent within the world, the West apart from it. But whenever there is an expression of the Transcendent (and an accompanying transcendental experience)... these differences are totally obscured" (54). The "differences between Ozu and Bresson are unified in stasis, the culmination of transcendental style. The Wholly Other, once perceived, cannot be limited by culture" (55).

I think, however, that these cultural differences may actually produce cracks within part three of Schrader's formula - stasis. It would be easy enough to say that these invalidate the formula. It could be, however, that they make it more interesting.

The three parts of his formula go like this.

1. The everyday: a meticulous representation of the dull, banal commonplaces of everyday living. (39).

This is not, for Schrader, "realism", precisely because it is so rigorous in removing the melodramas, full affects and interpretations that occur in everyday life (it is this attachment to psychology realism that removes most of Schrader's own films from the ambit of transcendental style ${ }^{(3)}$ ). This emphasis on the everyday requires, a great deal of selection and discipline. But this everyday is only a prelude - "to the moment of redemption...when ordinary reality is transcended".

2. Disparity: an actual or potential disunity between man and his environment which culminates in a decisive action. (42).

For Schrader, this is where it begins to seem that there might (must?) be more to life than the everyday - "the mountain may in fact not be a mountain". The decisive action involves an attempt to cut through the everyday, yet this attempt is not often obviously adequate to what it is attempting to express. The result is - a "sudden inexplicable outpouring of human feeling which can have no adequate receptacle ... an overwhelming compassion" (43). The only apparent explanation for this is spiritual. It cannot be explained by the cold environment, and seems too large for any one human to bear. This is not, however, the moment of the transcendent. It is rather the simple result of a period of tension and disparity between "a maximum of human expression and nonexpression... a potential disparity between man and nature" which is both a "spiritual emotion and spiritual schizophrenia" (it is here that we could perhaps situate much of what is so valuable about so many of Schrader's films). It is this tension that leads to the "decisive action",

.... totally bold call for emotion which dismisses any pretense of everyday reality. The decisive action breaks the everyday stylization: it is an incredible event within the banal reality which 
must by and large be taken on faith. (46)

There is the actual miracle of the raising of the dead in Dreyer's Ordet. There is Mouchette's self-drowning in Bresson's Mouchette. In Ozu's films these decisive actions are different, however. In Ozu's films, these decisive actions - these breaks with the everyday - seem surprisingly everyday themselves - a daughter smiles and at the same time is deeply moved by her sleeping father (in Late Spring - 1949, Japan), a father weeps after his daughter has just been married (in An Autumn Afternoon - 1962, Japan) (Deleuze, 1989: 14). Schrader attempts to justify their inclusion as decisive actions by invoking a conflict surprisingly similar to the conflict that informs Kant's aesthetic of the sublime (to which I shall return shortly). For Schrader these events in Ozu's films are decisive actions because the environments in which they occur are full of disparities and ironies. The emotions overflow their environment's (and their human expressors') capacity for expression.

As we come to the third aspect of transcendental style, it becomes obvious that this not only a semantic style (a setting up of oppositions) but a syntax - in Deleuzean terms a "politics of the line". Events in transcendental style occur in a certain order. First, banality. Secondly, disparity leads to a decisive action. However, the ground has been prepared now for this decisive action not to resolve anything within the world, not to reclaim the capacity for action, but quite the opposite. The transcendental style thus "transforms" the decisive action into a stasis. Thus, moving from station to station in our syntax of transcendental style, we have grand central (change trains for the beyond) --

3. Stasis: a frozen view of life which does not resolve the disparity but transcends it. (49)

It is here that the style finishes but transcendence takes off - perhaps even after the film (Mouchette would be the best example here). Obviously, whatever the reservations one may have about it, as a distilled description of transcendental style, Schrader's is a powerful one. It is an exemplary attempt to describe the operation of the transcendental style within film - whether the experience finally transcends culture or not. In fact, and as Schrader points out, it is important to note that he is not accounting for transcendental experience here (although he is obviously encouraging the move towards it as an aesthetic value).

Here I would note the similarity of Schrader's formula to the well-known formula for the Kantian sublime, where the "stasis" involved arises from contemplating a scene which brings reason and imagination into conflict. Although this is not the place for more than the most schematic discussion of Kant, I would like to emphasise the commonality between the transcendental (as opposed to the transcendent) in the Kant of Critique of Pure Reason, and transcendental style (as opposed to a comprehensible experience of the transcendent) in Schrader. In both, culture gets to have it both ways. It gets to avoid the transcendent in any direct sense (and the philosophical difficulties this might give rise to), but to save the transcendent at the same time, in the triumph of the transcendental subject's reason over imagination in the experience of the sublime, or the transcendental style and the experience of stasis. And in both cases the syntax of the experience is crucial. Neither Kant nor Schrader just propose elements of experience in a mixture. These are elements that are ordered and hierarchised. One begins with the everyday, with disparity, with life in miniature, with its contradictory activity that overwhelms a passive subject. This contradiction is felt and it is even expressed - but at the same time this feeling is unbearable and inexpressible. Even full expression is denied by this dysfunctional world! There is no adequate way to respond to the sensations the physical world forces upon one. Yet in all this the contradictory world - as perceived - is only a prelude - to stasis or the sublime where we finally triumph.

Triumph, however, is obviously not always the case. Here I want to return to Schrader's film Touch. He himself notes that his own films are not as "transcendental" as Bresson, Dreyer or Ozu's.

What is unusual in Touch is not that the ex-monk Juvenal fails to understand his gift of healing through touch. It is that he does not really seem puzzled by it either. There seems little disparity for him, little conflict. In fact the film is unusual precisely in that it outlines a series of possible conflicts (rip-off managers, religious bigots, media exploitation, sexual desire, a love interest) that do not in the end seem to have much of an effect on the main character. He seems to lack the need to understand or even think about the transcendent, so long as it can all fit into his daily life (which amounts to a standard romance which finishes with a drive into the distance in a fairly standard Hollywood pairing). In other words, in Touch, made long 
after the writing of Schrader's book on transcendental style, the immanent no longer seems such an enemy to the transcendent (the wisdom of age perhaps, the resolution of Schrader's own famous conflicts surrounding his Calvinist upbringing?).

The moment of most wonder occurs when Juvenal seems to lose his gift and attain the banal. Here we might say that the syntax of transcendental style is reversed. Juvenal suspects he can no longer heal and goes to that most everyday of places, the shopping centre, to try out his new found ordinariness. He tries to heal someone down on their luck, sitting on a bench. It fails. So much the better for him! (although his gift later returns on a television show - of course, everyone now thinks it's a fake). For him this failure seems almost a relief. More than this, and even better, he does not seem to care, even when the gift returns.

Going back through Schrader's own films more generally, one is struck by the banality of them, by a banality trying to express itself as strongly as the transcendent - but also at times by the failure of the transcendent to make any mark on the comprehensible world. There is even, at times, in films such as Mishima (1985, USA), or even Taxi Driver, an almost malicious transcendent. This seems the enemy of the expression of the immanent rather than the other way around. Of course, sometimes there is indeed the desire to transcend the banal, to reject the immanent world, and in many films, to find no joy in the banal except as a ritual leading to the transcendent. However, if one puts the Schrader-written Taxi Driver in this context, this is hardly a vindication of the drive towards redemption through the transcendent.

In addition, when Schrader's films do seem to head for the transcendent in his own films, this movement is sometimes parallelled by a hardly minimalist sensuality (Cat People - 1982, USA; Light Sleeper - 1992, USA; Mishima). This is a sensuality strangely echoed - but echoed in traces in crucially different ways - in the three film makers Schrader discusses in Transcendental Style in Film. Of the three, it is the Jansenist, Bresson, who is the purest ${ }^{(4)}$. He seems the most consistent anti-sensationalist. Yet one could argue that sensation, in the more regular sense, abounds all the more because of this constraint (the classic Christian tension no doubt). One can, for example, read the crucial moment in a film like Mouchette backwards here as well as forwards. Here, as I have mentioned, an everyday girl kills herself as a prelude to the moment of transcendence (not for her but for the film). She has lived a life that only ever betters itself to the level of the banal, but touches for the most part on the horror that for Bresson seems to lurk beneath the banal. For no reason at all, at the end of the film, Mouchette rolls down a hill next to a pond, not once, but almost ritually, three times. The third time she keeps going and disappears, quietly, into the water. What are we to make of this disappearance? For Schrader it is stasis. Is it escape to the other side? For us in the cinema at least? Or is there a huge amount of leakage between the sensuous nature of the act (rolling down the hill, plunging into the water - I seem to remember she is wearing a new dress) and the transcendence invoked by the ascetic style of film. Must any sense of transcendence at this point be admitted to be carried, not only by the syntax of transcendental style, but by sensation. If we begin "see" the transcendent, is it only because we "feel" it first. In this there is again the ghost of Kant - of the difference between transcendental aesthetics in The Critique of Pure Reason as being about the conditions of possible experience and the aesthetic of the sublime in The Critique of Judgement being about feelings of pleasure and displeasure, possible and real experience $^{(5)}$. I hope to further tease out the relation between these two in the rest of the paper.

Carl Dreyer's films are, of course, remarkably sensual and epitomise the leakage between the beautiful and the sublime in film. Here I especially mean the sublime ugliness of Vampyr (if ever there was a conflict between reason and imagination), or more particularly the famous eyes of Maria Falconetti in The Passion of Joan of Arc. Falconetti's eyes constantly break the horizon that would give sense to our vision to produce instead sensation within the film - Deleuze calls this film "the affective film par excellence" (1986: 106). In this film, famous for its use of close ups and for the agony on Falconetti's face as well as the constant wide eyed stare, we are no doubt in the realm of transcendental style. Nevertheless, for me it becomes obvious that the transcendent is only ever approached through a style because, only via this style, the transcendent can ghost the immanent. In addition, sense (whether the sense of the transcendent or of anything else) can only be captured within a style because sense must ghost sensation ${ }^{(6)}$. In other words, sense does not just move towards the transcendent - it also finds itself in the immanent, emerges within the immanent. It seems to me that, though one can argue that Bresson and Dreyer's films focus on this irresolvable disparity between sensation and sense precisely in order to push one through to the transcendental, one could just as easily argue that this disparity only enhances the sensation. Disparity puts on hold the putting on hold 
that sense would perform on sensation. This is partly because in both Bresson's films and Dreyer's there seems an undefeated erotic in sensation. It's all too enjoyable. And here I would suggest that there is always, as is well known, a great deal of ambiguity, of leakage, between the realms of transcendence and sensation. This is, of course, the point of theories such as Schrader's transcendental style and Kant's sublime but this ambiguity can also prove to be their undoing - depending on the direction in which you travel. There are several other planes of leakage I could discuss here - in particular between the everyday and the aesthetics as non-everyday (something well explored by artists this century). Maybe the transcendence/immanence distinction begins to make little sense - or perhaps its making sense is the problem.

\section{The Extraordinary as Misperception}

It is Yasujiro Ozu's films that provide an interesting working through of these problems for me, and I shall approach them via both Schrader and the discussion given by Deleuze in Cinema 2: The Time-Image.

As is well-known, in Ozu's Tokyo Story an elderly couple comes to Tokyo to visit some of their children and grandchildren. The film seems to narrate a conservative story about family values (no vampires or burnings at the stake here as with some of Schrader's other favourite film makers). The grandparents are: patronised by their daughter, their son and his wife; entertained by some of their grandchildren; sent on a holiday to get them out of their ungrateful children's hair; and finally, exhausted, travel back to their hometown, at which point the heart condition of the grandmother finally catches up with her and she dies, leaving the grandfather sitting quietly alone in his house.

Significantly both Schrader and Deleuze focus on a sequence at the end of the film. In this sequence there is a mountain rising up above the town in which the grandfather sits alone in contemplation, in the same fashion as he has in the beginning of the film with his wife. (When I say contemplation here I do not mean deep meditation. He has not transported himself elsewhere. He is still able to greet a neighbour who passes the window.) This final sequence creates a kind of horizon that puts everything into context but this is a horizon that works differently for Schrader and for Deleuze. I will talk about both this sequence and another, upon which only Schrader focuses. The other scene is that in which the grandmother (Chieko Higashiyama) visits the daughter-in-law (Setsuko Hara) who was married to the grandmother's dead son. But first the mountain.

What is interesting about Schrader here, considering his predilection for disunity, is that he gives a good analysis of "Ozu's normal emphasis on unity rather than disunity, on aware rather than conflict" (36). Nevertheless, in a rather typically Christian interpretation of Zen, Schrader goes on to use the mountain, firstly, to put everything into perspective and, secondly, to reinvoke the transcendent (as a nature devoid of conflicts with culture, or of this conflict transcended). He writes that -

The final shots of Ozu's films ... are reaffirmations of nature. These shots may depict something as traditional as a mountain, or it (sic.) may incorporate such contemporary elements as a boat on a river, or a smokestack. These scenes are the final codas, the final silences and emptiness. Ozu does not eliminate the conflict between man and nature by plot maneuverings or psychological revelations, but by merging man and nature with Zen thought and life. He does not so much eliminate the conflict between man and nature as, you might say, he transcends it. (1989: 37)

For me, this final moment of transcendence, of a reaffirmed horizon, is matched in importance by a less signalled moment in the film. This is a sequence involving touch, and at that, a very different kind of touch to Dreyer's teeth of the vampire or Joan's burning at the stake, or even the assaults that poor Mouchette suffers in Bresson's film. In this scene the weary grandmother visits her daughter-in-law's rather simple flat for the night and is given a little shoulder massage by the daughter-in-law. The grandmother and the daughter-in-law share the death of their son/husband and it seems this touch opens an acceptance between them about this. Schrader sees only the focus on irony in this scene as the grandmother says - "What a treat to sleep on my dead son's bed". He treats the grandmother as almost stupid. He sees only the disparities that break up the horizon or perspective of the everyday and lead to a conflict of sense - a conflict that will eventually move us to the new horizon beyond which one finds the transcendent.

This is not, however, a conflict parallelled in the sensations of this scene at all. The sensations of the bed and of the little massage here are clearly those of comfort but Schrader fails to mention them in this light. 
Schrader misses, in short, the touch here that also, like the transcendent, breaks or extends horizons, though in a different way. The touch breaks the impact of death within life, at least long enough for the grandmother to tell the daughter-in-law to move on with life, to forget her dead husband. For me this touch breaks the sense of perspective, the need for a fixed horizon, in order to transform the situation into something new. Yet if this is true it obviates the need for the transcendence that Schrader writes is to come. It is as if Schrader misses the light within the frame in order to have a light beyond (and both characters here do shine - dressed as they are in light-coloured clothes against the drab background - not all of Ozu is so evenly lit as we are sometimes led to believe). This touch is undoubtedly an everyday action that redeems the whole situation from within, not beyond.

Deleuze does not discuss this scene but he does discuss the mountain and Schrader.

Generally, Deleuze loves Ozu as much as Schrader, and just as Schrader credits Ozu with the transcendental style, so Deleuze, in Cinema 2, credits Ozu as the "inventor" of Deleuze's beloved "opsigns and sonsigns" (1989: 13) These have a relation to an immanent virtuality rather than transcendence. In Deleuze's understanding the film moves not towards transcendent style but towards the refraction of the immanent that can accommodate a new type of immanent complexity and fluidity. Horizons are not crossed but dispersed and reconfigured. Deleuze, unlike Schrader, has no desire to leave the everyday (which here I will unwisely conflate with the immanent) in favour of a transcendent. Again, I will quote at length -

..it is definitely not the case, with Ozu, that we get the remarkable and the ordinary, limitsituations and banal ones, the former having an effect on, or purposely insinuating themselves into, the latter. We cannot follow Paul Schrader when he contrasts, like two phases, "the everyday" on the one hand, and on the other, "the moment of decision", "the disparity", which introduce an inexplicable break or emotion into daily banality. This distinction would seem strictly more valid for neo-realism. In Ozu, everything is ordinary or banal, even death and the dead who are the object of a natural forgetting. The famous scenes of sudden tears (that of the father in $A n$ Autumn Afternoon who starts to weep silently after his daughter's wedding, that of the daughter in Late Spring who half smiles as she looks at her sleeping father, then finds herself on the verge of tears...) [these scenes] do not mark out a strong period which might be contrasted with the weak periods in the flow of life, and there is no reason to suggest the emergence of a repressed emotion as "decisive action". (1989: 14)

Deleuze goes on to discuss the manner in which Leibniz and others explain the extraordinary as a misperception. The extraordinary is a misperception that comes about through an incomplete understanding of the way in which "the oddest adventures are easily explained, and that everything is made up of ordinary things". In a sense every horizon, though it may give vision a ground for sense, is inevitably not as absolute as it seems. Rather it is a random line drawn through the actuality of circumstances and we know that one of our fascinations in gazing at horizons (in the twentieth century at least) has been to watch them move, and to learn that we do not fall off the edge of the world beyond them. In regard to visions of mountains, Deleuze goes on to write -

On this point it seems to us that nature does not, as Schrader believes, intervene in a decisive moment or in a clear break with everyday man. The splendour of nature, of a snow-covered mountain tells us one thing only: everything is ordinary and regular, everything is everyday! Nature is happy to renew what man has broken....And, when a character emerges for a moment from a family conflict or a wake to contemplate the snow-covered mountain, it is as if he were seeking to restore to order the series upset in this house but reinstated by an unchanging, regular nature... (15)

In other words, it is the restoration of the regularity of natural series that we cannot understand that is important, not the seemingly transcendent break. There is nothing other than these series, and as much as we might seek the drama of the transcendent break, this too is only a moment of the series that will fold back into the immanent series from which it has arisen.

I would suggest also that the interplay and confusion of the Kantian sublime, also comes into play here, but with a new multidirectionality that does not lead out of the world (even of culture, even to "reason" and away from sensation) but back into it. This time the confusion is not only a move towards the sublime 
and the affirmation of reason. It can also signal, perhaps along even the same pathways but in a different direction, an undoing of the sublime and the transcendental subject. This is the unknotting of imagination and reason in favour of the world that touches and is touched.

I would tentatively call this a "reverse aesthetic" in that it moves aesthetics such as Schrader's and even perhaps Kant's backwards. In fact, this is not only a reverse aesthetic but perhaps also a shattering in total of the syntax of certain aesthetics, perhaps a shattering of the aesthetic itself (considered as a form of judgment, though obviously not as the understanding of sensation) from within. This shattering is not in the service of the grand goal of the traditional aesthetic, which is to say the positing of divisions as disparities, as horizons between ground and sky, followed by a movement beyond these carefully constructed horizons. This shattering is rather in the service of a return of the aesthetic to life, to the everyday, to the world, to the expression of emotion (that occurs literally as we watch this film), to the effect of a touch which guarantees the power of the immanent to affect, to transform ${ }^{(7)}$.

\section{Touches, Bodies and Fields}

The simple sensuality of films at such moments raises the general question of sensation within the aesthetics with which I began. As Peter Canning puts it simply, "Cinema works affectively" (348). Melissa McMahon teases out the meaning of this for film theory, or we could simply say, assumptions about the body within film spectatorship.

What is also in question here is the relation between "theory" and "cinema" itself - because if the point of contention is the way in which the body can be subordinated to a transcendent concept, in the form of a subject, a meaning, or a narrative, then this problematic extends to the body of cinema as a whole, and its relationship to the critical subject and spectator ... activities like ... watching a film ... are not extensions of the body or the incorporation of the environment into the body, both of which presuppose a boundary, a division between inside and outside, but are rather the forming of a "machine" around the points of connection. The relations of forces constitute a new "body", an assemblage that disassembles the unity of subject and object. (McMahon: 127 \& 132)

The first point here is that the distanciation of vision in films is always accompanied by a necessary and absolute proximity, carried by the points of touch and transformation of the series discussed above. "It" is up on the screen, but "it" is also quite literally in my eye. Put simply, as in the well-known Godard saying, "it's not blood" (i.e. representation to a distanced knowing subject) "it's red" (i.e. sensation). This is true of any attempt at distanciation. That which I judge is also "in my eye". As Bringing Out the Dead understands so well, whether in the violence of judgment or in compassion, the blood is on my hands. My sovereign enemy lies at the heart of my own sovereignty. The transcendent beyond is already soaked through with everything that is immanent to me (which is what Schrader and Deleuze, Scorsese and Ozu, tell us in their very different ways).

Of course, as subjects (if such things could be said to exist), and through the Idea of the subject, we are nearly always seeming, at least, to transcend sensation. The very notion of the human has been predicated on being able to transcend sensation in favour of interpretation and transcendental integrity, if not transcendent departure from at least the sensations of this world. The aesthetic, when I will now characterise at its most basic, and against judgment, as the movement of sensation and of this sensation over a plane of immanence - light on the retina, a simple touch, and so on - is therefore a crucial zone in deciding the fate of sensation. Is it going to be cancelled out in favour of the transcendental subject (even in concepts such as the sublime)? Is it going to reaffirm the assumptions of the already known? Or is it going to open up the possibilities of expression on the plane of immanence?

As Brian Massumi put it when writing on Stelarc, this is a peculiarly contemporary question. Massumi notes that, as seen in so many films such as Touch or Bringing Out the Dead, we are witnessing the beginning of a questioning of our everyday being in which --

...the everyday bodily and subjective integrity of the person actually submerges, rather than expresses, the intensity of perception, in its synaesthetic and kinesthetic dimensions. (1997)

For Massumi, artists such as Stelarc (and, at times, I would argue, the operation of sensation in the cinema 
as well as some new media developments) are using "technological expressions and extensions of human expression" as ways of bringing the body more into contact with the world - its sensate disparities and serial archipelagos or clusters of sensations. Many of these aesthetic uses of technology "find their 'unity' in dispersal and are fundamentally asubjective". As Massumi points out, such an engagement with these machines is creative because it enables a fuller engagement with the world through sensation while suspending the gathering together of these sensations under the transcendence of the "human". Here again we move far beyond the normal understandings of the postmodern, which actually starts to look a little old fashioned in its nihilism when compared with the planes of immanence opened up in these engagements. Massumi notes that --

The post-human is not post-sensual. It is sensation and perception that have been non-human all along. There is no need for apocalyptic imagery of the cyborg. What is called for is experimental connection to and continuation of the inhumanity in all of us. (1997)

Here I would return to the assertion that touch and vision in the cinema can be formulated very differently when one conceives of them as both independent and linked points in archipelagoes of sensation - between light and touch, between the touch on the screen and that touch as it reaches our eye, between the sensation in the eye and other sensations registered in our bodies, between these movements and the creation of ideas as sensate (perhaps as in the everyday revolution brought about by compassion in the massage scene I have talked about in Tokyo Story - a compassion that can now be seen to need its non-human elements, its archipelagos of sensations).

\section{Seeing Bodies}

All this is to claim that the audiovisual is not isolated from the other senses ${ }^{(8)}$, something clearly reworked through in film time and again. In fact, this is arguably the very basis of the ongoing work that film performs. Perhaps film itself is responsible for such ideas, ironically given the emphasis on the divorce from the body in many theories of spectatorship. Film gives us our most complex working through of the relations between bodies and light, of the sense of bodily relations that precedes cultural effects, of those effects themselves and their feedback into relations between bodies.

Deleuze suggests that one way of looking at bodies in films is in terms of the "everyday" body and the "ceremonial" body (1989). Both imply bodies as sites of passage. They are not mutually exclusive. The important thing is the passages between one and the other. These terms work well with reference to Bringing Out the Dead.

For Deleuze the everyday body has two prime conditions, that of tiredness and that of waiting. Its tiredness shows that the body is never in the present but always an embodiment of a before and after, and nothing could make this clearer than Frank in Bringing Out the Dead. He cannot sleep for most of the film, only once briefly in his new friend Mary's apartment. At the end, his passage seems complete when he falls asleep again with her, and darkness turns to light as if the heavens have finally opened. Yet Frank also has easy access to the ceremonial body, namely that of the uniformed ambulance driver. Much more than Travis as taxi driver in Taxi Driver, Frank struggles with this role, even as he waits for it to "work", which in his case means saving another life. Indeed the film is full of ceremonial roles: drug dealers, doctors, prostitution. Deleuze suggests that in such roles the "disappearance of the visible body is achieved" (1989: 190). And it is true, yet the passages between the everyday and the ceremonial, and back, are what are important, demonstrated most clearly perhaps in the visibly pregnant prostitute who gives us a clear Deleuzean optical sign.

In this the body has a strange relationship to thought, one that may clarify the nature of our question as regards the body and cinema. In one of his clearest statement about life and thought, one which we should apply to the cinema when examining the question of the body in cinema, Deleuze takes on board the consequences of a fairly rigorous materialism, one when life and the body come first and we cannot think without them. In all this, however, a body is not as simple as it might seem. Like thought, it is a question of immersion in relations. Brian Massumi, in another context writes that "relationality makes for a more materialist (if less objective) account than that of science" (2002: 228) and we should perhaps remember the scientific aims that lay behind the origins of the psychoanalysis and semiotics that have so influenced film theory. Deleuze writes of a philosophical reversal here that has much to do with the "reverse aesthetics" 
discussed earlier.

'Give me a body then': this is the formula of philosophical reversal. The body is no longer the obstacle that separates thought from itself, that which it has to overcome to reach thinking. It is on the contrary that which it plunges into or must plunge into, in order to reach the unthought, that is life. Life will no longer be made to appear before the categories of thought; thought will be thrown into the categories of life. The categories of life are precisely the attitudes of the body, its postures. (1989: 189).

It would be easy enough to try and give this a fixed context such as the "cinematic apparatus" but the context is not a context so much as an openness. "The attitude of the body relates thought to time as to that outside which is infinitely further than the outside world".

Some confusions which bear upon touch, thought and cinema perhaps need to be resolved here.

Firstly, again in another context - that of the relation of science to a more progressive and rigorous materialism - Brian Massumi has differentiated between emotion and affect in a way which enables us to consider two kinds of field relevant to the relations between touch on the screen and what occurs between screen and cinema audience.

Reserve the term 'emotion' for the personalized content, and affect for the continuation [that excess which 'escapes its contextual containment - its objectivity' in order to enable 'continuing activity']. Emotion is contextual. Affect is situational: eventfully ingressive to context. Serially so: affect is transsituational. As processional as it is precessional, affect inhabits the passage. It is pre- and post-contextual, pre- and post-personal, an excess of continuity invested only in the ongoing: its own. Self-continuity across the gaps [such as that between the screen and the audience perhaps]. Impersonal affect is the connecting thread of experience. It is the invisible glue that holds the world together. In event. The world-glue of affect is an autonomy of eventconnection continuing across its own serialized capture in context. (2002: 217)

Frank giving mouth-to-mouth to Noel. New York itself. A daughter-in-law in Tokyo Story massaging the tired body of her mother-in-law. These scenes together provoke the thought of the world - not a context but the world as situation - as transsituation or, in fact, all of these and an outside immanent to these.

If there is a form of "open capture" appropriate to this transsituations, it is probably the "gest". Deleuze describes a movement towards (Brechtian) gest, which is our way of dealing with this "worldness" as opened up to us in the relational gestures of such scenes. In Deleuze's terms the gest is "bio-vital, metaphysical and aesthetic" (1989: 194) and "not only social" (315). The gest suggests not just a fixed outside or beyond (and thus an inside), but an openness. Of course, our relations, especially within the cinema and as shown in the gest, deal with both these more determined outsides and less determined openness. For example, the gest is not just something, as it is often viewed, which "sums up" the social context. It is that which, like Tom, Frank and Noel in combat and compassion, exceeds these contexts. For Deleuze, the gest in "general is the link or knot of attitudes between themselves, their coordination with each other, in so far as they do not depend on a previous story, a pre-existing plot or an action-image" (192). There is a "direct theatricalization of bodies" of bodies here that "takes place independent of any role". In short, the attitudes of the body already disrupt our neatly thought assumptions of roles and action in the cinema, because they already put the "series of time" (195) into the present, making clear a before and after, robbing it of its presence. The gest, however, is a "different time-image, the order or organization of time, the simultaneity of its peaks, the coexistence of its sheets". Again the important thing is the "passage from one to the other", lived out in archipelagos of sensations. It is the resulting "complexity" that is simply out of the reach of many accounts of cinema.

Stern follows this to suggest that the bleed between even the ceremonial of "going to the movies" as an "event" on the one hand, and the everyday impact of the movies on the other, is two way. She writes that we "project after-images elsewhere, and onto the movies we project scenes and memories and forgotten sensations" (31). Moreover, this two-way bleed of sensation slips around through time. She points to the "sensuous image" as containing an "essential ambiguity, a contradiction between time lost and time regained" (39). To sum all this up, we could perhaps write (only somewhat paradoxically) that the immediacy of sensation does not 
occur all at once. It is somewhat more pervasive than that, and at the same time more evasive. In fact, as regards sensation, nothing could be more erroneous than the notion of presence if we regard presence as instantaneous presents. One simple reason for this is that it takes time for sensation to travel through its circuits, and longer through the archipelagos involved. It takes more time, when these circuits are broken, or are established immanently on the hop.

In short, we misunderstand immanence if we reduce it to an impossible immediacy and a restricted locale rigidly separated from its environment and temporality. Immanence is instead something of a shifting field that constructs and pulls apart time, space, bodies as it shifts. It is in this field that we need to locate sensation, and more specifically, the way that affect works within the cinema. It is in this field, for example, that we can understand how touch on the screen might impact upon the audience.

\section{Thinking Film}

In sum, in thinking about film we can go at least two ways, and both are perhaps unavoidable. We can attempt to close the cinema into the circuits of theory or we can open up theory to affect, to transsituation. Shaviro puts this as a "tension between the desire to reproduce and a desire to keep at a distance the voyeuristic excitations that are its object" (14). For him, the latter is too much in control in film theory developing a closed system approach. For Shaviro, the theoretical motivation for such theorisation is not so much philosophical or even scientific. It is based instead upon such things as "an idealist's fear of the ontological instability of the image, and of the materiality of affect and sensation" (15). He subsequently reverses a lot of the determinations of film theory. For example, the gaze is no longer primary in relation to its devouring of images, but rather, images that "solicit and sustain - while remaining indifferent to - the gaze" (20). He points to the Hegelianism of much film theory, arguing against this that -

The Hegelian argument against raw sensation is valid only to the extent that sensation is equated with cognition and attributed to a fixed subject. But now, perception can no longer be subsumed under reflective consciousness, or under cognition and judgment; instead, it marks a limit beyond which these can never extend. Sensation is disengaged from the transcendental conditions that are supposed to ground and organize it, as from the referential coordinates that allow us to locate and preserve it. (28)

Shaviro goes on to point out that the cinema makes us "stay within the orbit of the senses. I am confronted and assaulted by a flux of sensations that I can neither attach to physical presences nor translate into systematized abstractions" (32). We still, however, try to do the latter, often reflecting upon this productively. Stern points out that Taxi Driver, for example, takes this up and becomes as much a "meditation on the violence of projection" (166) as a meditation on violence itself. Travis is desperate to close the circuit around that he senses.

In this sense, Bringing Out the Dead is a counter-argument, or better, a counter-experience. Frank here is also struggling to deal with the immanent assault of sensations. He even has a number of theories about it all, which include heaven and hell, good and evil and so forth. Yet he is constantly propelled out of these theories and constantly opening the failed circuits that attempt to explain the world as anything more than the world. The climax of Taxi Driver is, despite everything, a closure that fails to resolve anything. The climax of Bringing Out the Dead is an opening that resolves everything, but only in favour of the world. Then again I've always liked romance.

\section{Notes}

1. I am indebted to Lone Bertelsen for this point.

2. Although for a critique of Schrader's approach to Bresson, see Burnett, 2004a and 2004b.

3. "... with regard to stylization, I'm quite different from Bresson. The reason why I don't make transcendental films, the reason I don't have transcendental style, is that I believe in something that is anathema or contrary to the whole notion of transcendental cinema. I have my roots in psychological realism and audience identification with character, whereas the whole notion of transcendental style is based on repudiating psychological realism. I've always preferred a kind of nineteenth-century, existential, psychologically 
real type of character. We may be moving into a post-existential era--I hope not, although there are signs about us that we are--in which case the work that I do, and this approach to characterization, will be truly anachronistic" (Schrader in Bliss).

4. William Bogard suggests, after Deleuze, that in fact sense prefigures language, in the relations between bodies.

5. Burnett (2004a) points to the sensuality in Bresson's films, but it is no match for Schrader's of course.

6. Daniel W. Smith has written that, "Aesthetics since Kant has been haunted by a seemingly irretractable dualism. On the one hand, aesthetics designates the theory of sensibility as the form of possible experience; on the other hand, it designates the theory of art as a reflection on real experience" (Smith: 29).

7. This disruption explains the transformative nature of touch within the everyday, as demonstrated by the power of the little massage in Tokyo Story (and finding another context in the tango that Manning discusses). The disruption is clearly related to a politics of touch. Manning writes of the power of touch to break hierarchies and syntaxes, "What we know about the state is that it cannot operate without violence: state power cannot exist unless it holds the ultimate and exclusive right to force. The body, on the other hand, cannot exist if it is not touched. The body is therefore about reciprocity, whereas the state is concerned with sovereignty. When the state takes over the body, it attempts to create a bond of reciprocity that is solely hierarchical. When the body leaves the state, what the body finds is the capacity to create movement through space and space through movement. The body departs from a sovereign territorialized bounded space to a space that traverses time, a space that cannot be cleanly delineated but through which a juxtaposition and a convergence take place that multiply space through textual layerings".

8. For a history of the philosophy of touch in relation to the other senses, and for a comprehensive discussion of a politics of touch, see Manning. She writes, for example, that the "body is a sensory apparatus. Yet, the senses are difficult to grasp, difficult to condense into theories of movement. For the body senses in layers, in textures and juxtapositions that defy strict organization into a semiotic system. This is already apparent in the early work on the senses, from Aristotle to Augustine to Diderot, where we find not a convergence of theoretical understandings of the senses, but a continual re-theorizing, a re-imagining of where the senses exist in relation to the body and the mind".

\section{References}

Bliss, Michael (2000) "Affliction and Forgiveness: an interview with Paul Schrader - filmmaker." Film Quarterly (Fall).

Bogard, William (1998) "Sense and Segmentarity: Some Markers of a Deleuzian-Guattarian Sociology." Sociological Theory 16(1): 52-74.

Burnett, Colin (2004a) "Reassessing the Theory of Transcendental Style, Part 1: A Case Study of Le Diable Probablement." Offscreen .

Burnett, Colin (2004b) "Reassessing the Theory of Transcendental Style, Part 2: Le Diable as a Reflection on Film's 'incommunicability'." Offscreen.

Canning, Peter (2000) "The Imagination of Immanence: An Ethics of the Cinema." In Flaxman, Gregory (ed.) The Brain is the Screen: Deleuze and the Philosophy of Cinema. Minneapolis, University of Minnesota Press: $327-362$.

Deleuze, Gilles (1986) Cinema 1: The Movement-Image. Minneapolis, University of Minnesota Press.

Deleuze, Gilles (1989) Cinema 2: The Time-Image. Minneapolis, University of Minnesota Press.

Manning, Erin (2003) "Negotiating Influence: Argentine Tango and a Politics of Touch." Borderlands 2(1). 
Marks, Laura U. (2000) The Skin of the Film: Interculture Cinema, Embodiment and the Senses. Durham, Duke University Press.

Massumi, Brian (1997) "Stelarc: The Evolutionary Alchemy of Reason." .

Massumi, Brian (2002) Parables for the Virtual: Movement, Affect, Sensation. Durham and London, Duke University Press.

McMahon, Melissa (1995) "'Fourth Person Singular': Becoming Ordinary and the Void in the Critical Body Filmic". in Jayamanne, Laleen (ed.) Kiss Me Deadly: Feminism and Cinema for the Moment. Sydney, Power Publications: 126-146.

Schrader, Paul (1972) Transcendental Style in Film: Ozu, Bresson, Dreyer. Berkeley, University of California Press.

Shaviro, Steven (1993) The Cinematic Body. Minneapolis, University of Minnesota Press.

Smith, Daniel W. (1996) "Deleuze's Theory of Sensation: Overcoming the Kantian Duality". in Patton, Paul (ed.) Deleuze: A Critical Reader. London, Blackwell: 39-56.

Stern, Lesley (1995) The Scorsese Connection. Bloomington, Indiana University Press.

Stiegler, Bernard (2001) La technique et le temps 3. Le temps du cinéma et la question du mal-être. Paris, Galilée.

\section{Author Information}

Andrew MURPHIE is an Australian academic who has published on performance and the visual arts, popular music, film and contemporary cultural theory (particularly the work of Gilles Deleuze and Félix Guattari), virtual media, network ecologies and digital aesthetics. He is the co-author with John Potts of Culture and Technology (Palgrave, 2003) and editor of the Fibreculture Journal. He is also interested in the cultural effects of models of cognition and perception. 